\title{
Greves de massa ou apassivamento da classe trabalhadora
}

\author{
Mass strikes or the pacifying of the working-class
}

\author{
Mauricio MULINARI* \\ http://orcid.org/oooo-0002-9271-6983
}

\begin{abstract}
Resumo: O presente artigo tem como objeto o confronto entre a teoria do apassivamento da classe trabalhadora e a nova realidade inaugurada no Brasil a partir de 2012: a reascensão das greves. Diante disso, procuraremos colocar em questão a teoria, gestada ao final da primeira década do século XXI, de que a classe trabalhadora estaria vivendo um período de apassivamento de suas lutas. Buscaremos uma análise conceitual que aponte os limites dessa perspectiva, orientando os esforços para iniciar a compreensão desse novo período inaugurado na história brasileira e tendo como passo fundamental o resgate da teoria marxista da dependência.

Palavras-chave: Greves de massa. Apassivamento da classe trabalhadora. Teoria marxista da dependência.
\end{abstract}

Abstract: This article has as object the impass beetween the working-class passivity theory and the new reality inaugurated in Brazil after 2012: the resurgence of strikes. We will seek to question the theory conceived at the end of the first decade of the 21st century, which defends that the working class was experiencing a period of passiveness on their struggles. We will seek a conceptual analysis that points out the limits of this perspective, leading the efforts to start a comprehension of this new period inaugurated in Brazilian history, which has as its fundamental step the rescue of the marxist theory of dependence.

Keywords: Mass strikes. Working-class passivity. Marxist theory of dependence.

Submetido em: 28/10/2019. Aceito em: 26/03/2020.

\section{Introdução}

$\mathrm{D}$ epois de longos 15 anos de baixa mobilização política da classe trabalhadora brasileira, o ano de 2012 marcou uma inflexão. Se entre 1997 e 2011 o país verificou uma média anual de aproximadamente 400 greves ao ano, a partir de 2012 passamos a registrar um enorme salto grevista. Foram quase 900 greves em 2012, em torno de 2 mil greves ao ano entre 2013 e 2016 e valores próximos a 1,5 mil greves tanto em 2017 quanto em 2018 ${ }^{1}$. Os dados, recentemente compilados pelo Departamento Intersindical de Estatística e Estudos Socioeconômicos (DIEESE), são muito elucidativos do momento de ampla agitação política que passamos a viver após a queda dos preços

* Economista. Mestrando do Programa de Pós-graduação em Serviço Social da Universidade Federal de Santa Catarina. Técnico do Departamento Intersindical de Estatística e Estudos Socioeconômicos (DIEESE, Florianópolis, Brasil). Av. Mauro Ramos, 1624, $1^{\circ}$ andar, Centro, Florianópolis (SC), CEP.: 88020-302. E-mail: mauriciomulinari@gmail.com.

1 DIEESE. Sistema de Acompanhamento de Greves (SAG-DIEESE). copiar e redistribuir o material em qualquer suporte ou formato, bem como adaptar, transformar e criar a partir deste material para qualquer fim, mesmo que comercial. O licenciante não pode revogar estes direitos desde que você respeite os termos da licença. 
dos produtos de exportação em 2011 e ajudam na melhor apreensão do sentido histórico dos tempos que se abriram a partir de então.

Antes disso, no entanto, aqueles anos de baixa mobilização (1997-2011) formaram o quadro de fundo que levou um conjunto de autores a formular a tese do apassivamento da classe trabalhadora. Na descrição de Iasi (2013b), como síntese do fechamento daquele período, “[...] estamos diante de um longo ciclo que resultou em um processo de transformismo, apassivamento da classe trabalhadora e recuo em sua consciência de classe que expressa uma profunda fragmentação e derrota política dos trabalhadores" (IASI, 2013b, p. 68).

Após essa expansão recente, os dados compilados também pelo DIEESE para o primeiro semestre do ano de 2019 novamente demonstraram retração significativa nas greves. Assim verificado, o presente artigo tratará de analisar o novo ciclo grevista inaugurado em 2012, buscando evidenciar suas causas e limites e questionando a tese de apassivamento da classe trabalhadora. Assim, tentaremos encontrar elementos para melhor caracterizar os nossos tempos de profundas rupturas políticas.

\section{$O$ apassivamento da classe trabalhadora}

Vários autores brasileiros formularam o dito apassivamento da classe trabalhadora ${ }^{2}$. A tese surgiu em torno do processo de transformismo que abateu a estratégia democráticopopular. De fator de mobilização e articulação da luta sindical e popular nos anos 1970, 80 e início dos 90, a estratégia acabou por se conformar à ordem burguesa nas décadas seguintes. A partir de sua vitória eleitoral em 2002, os governos comumente tratados como populares, por sua vez, trataram de administrar a ordem do capital em todos os seus condicionantes. O Partido dos Trabalhadores (PT), fundado em 1980, que propunha uma ruptura revolucionária com o capitalismo, passava então a defender as amplas alianças com a burguesia, o desenvolvimento capitalista nacional e a 'inclusão dos pobres no orçamento' através de políticas focalizadas orientadas pela cartilha do Banco Mundial. Tudo isso foi embalado pelo discurso em torno do diálogo social que, na prática, servia como dissimulador dos pactos feitos pelo alto entre a classe dominante e os altos escalões sindicais - pactos que estavam muito longe de garantir a universalização substantiva e igualitária dos direitos sociais (FONTES, 2010).

Diante dessa metamorfose na estratégia democrático-popular capitaneada pelas direções petistas foi possível ao capital estabelecer um novo ciclo de hegemonia a partir das eleições de 2002, preservando e reforçando a democracia de cooptação como forma de governo. Pelas mãos dos governos de Lula da Silva e Dilma Rousseff foram garantidos os interesses da acumulação capitalista através de um amplo pacto de classes, que teve como pressuposto e produto central o desarmamento ideológico da classe trabalhadora, ou seja, seu apassivamento (IASI, 2013a, p. 30).

\footnotetext{
2 Para fins didáticos, concentraremos os esforços explicativos na formulação de Mauro Iasi elaborada em dois artigos do primeiro semestre de 2013, elucidativos da força que a tese do apassivamento ganhou naqueles anos que antecederam as grandes mobilizações de junho de 2013.
} 
Para Iasi (2013a, p. 3), os embriões da democracia de cooptação e do apassivamento que ela produziu na classe trabalhadora já estavam contidos na própria formulação original da estratégia democrático-popular. Indicando que o comportamento político da classe trabalhadora não pode ser compreendido nem como mera intencionalidade subjetiva, nem como uma simples determinação da realidade objetiva, o autor critica a concepção que atribui a ampla passividade daqueles anos apenas ao crescimento econômico do período do governo Lula da Silva e à sua capacidade de entregar migalhas à classe trabalhadora. Dessa forma, em seu entendimento, o foco tem que se voltar para a própria estratégia determinante na condução da ação política do referido ciclo histórico.

Assim feito, o autor busca em Caio Prado Jr. (1978) e Florestan Fernandes (1976) os germes da estratégia democrático-popular. Na sua concepção, foram eles que melhor formularam a crítica à estratégia da Revolução Democrática Nacional, hegemônica no pré-golpe de 1964 sob a batuta do PCB e, posteriormente, derrotada pela ditadura militar brasileira. Para ambos, a revolução socialista seria inviável naquele momento e o centro da luta seria a apresentação das demandas democráticas dos trabalhadores que, por não poderem ser incorporadas pela ordem burguesa autocrática, tratariam de criar um impasse ‘dentro da ordem' que só poderia ser resolvido 'fora da ordem' (IASI, 2013a).

Iasi aponta que os autores referenciados formularam elementos do devir histórico em sua crítica ao passado. Tais elementos necessariamente passaram a ser apropriados pela estratégia democrático-popular, encarnada em sua totalidade pelo PT, que a utiliza como elemento de diferenciação da força hegemônica anterior: o PCB e sua estratégia de Revolução Nacional Democrática.

Entretanto, se no início do processo de afirmação enquanto força hegemônica o PT e sua Central Única dos Trabalhadores (CUT) precisam necessariamente apresentar-se em todo o radicalismo original de autores como Florestan e Caio Prado, no decorrer da década de 1990 e nos anos 2000, o partido vai passando por um largo processo de transformismo, abandonando formulações originais e as substituindo por proposições adequadas justamente à administração dos negócios da burguesia. Esse transformismo das direções políticas que conquistaram hegemonia no período de expansão das lutas populares, rebaixando logo em seguida o radicalismo de suas propostas, carrega consigo toda a classe trabalhadora, que adere à democracia de cooptação e subordina-se ao apassivamento de suas lutas (IASI, 2013a, p. 22-27).

\section{As greves: combatividade ou passividade da classe?}

Para além do aspecto subjetivo, elaborado acima com base na categoria transformismo de Antonio Gramsci, é preciso apreciar objetivamente se, de fato, passamos por um longo período de baixa atividade política da classe trabalhadora. Trotsky (1967, p. 48-49 ), ao analisar a Revolução Russa, colocava que uma das condições para a explosão revolucionária no país foi o fato de que o rápido desenvolvimento capitalista em alguns centros urbanos havia constituído uma classe operária que, já no início do século XX, 
iniciava uma longa marcha de greves políticas³. Essa marcha se estenderia - com avanços e retrocessos - de 1903 até 1917, funcionando como um ariete dirigido contra a fortaleza do absolutismo.

Já o filósofo brasileiro Álvaro Vieira Pinto (1962, p. 42-45), demonstrava que, se na aparência as greves eram o mero ato de cruzar os braços e parar de trabalhar, na essência se tratavam de momentos fundamentais de ganho de consciência para a classe trabalhadora. A classe deixava de trabalhar para outrem, sendo objeto da exploração capitalista, e passava a trabalhar para si mesma. Assim, mesmo quando a greve restringia-se aos aspectos econômicos corporativos imediatos, ela não era apenas isso. Na prática, pela vivência coletiva dos trabalhadores em confronto direto com o capital e o Estado, a greve trata de desvelar embrionariamente os pressupostos do socialismo: a emancipação dos trabalhadores e da sociedade.

Também para Lenin (1924), as greves ensinavam os operários a unirem-se contra os capitalistas e funcionários do governo. Chamava assim a greve de escola de guerra, onde os operários aprendiam a desfechar a guerra contra seus inimigos em busca da emancipação de todo o povo e de todos os demais trabalhadores do domínio do capital e do Estado.

Tendo as greves como indicadores da 'temperatura' da luta de classes no Brasil, os dados a seguir comprovam algo fundamental: a segunda metade dos anos 1990 e a primeira década dos anos 2000 de fato marcam um claro refluxo na luta dos trabalhadores.

\section{Gráfico 1 - Número de greves no Brasil (1983-2018)}

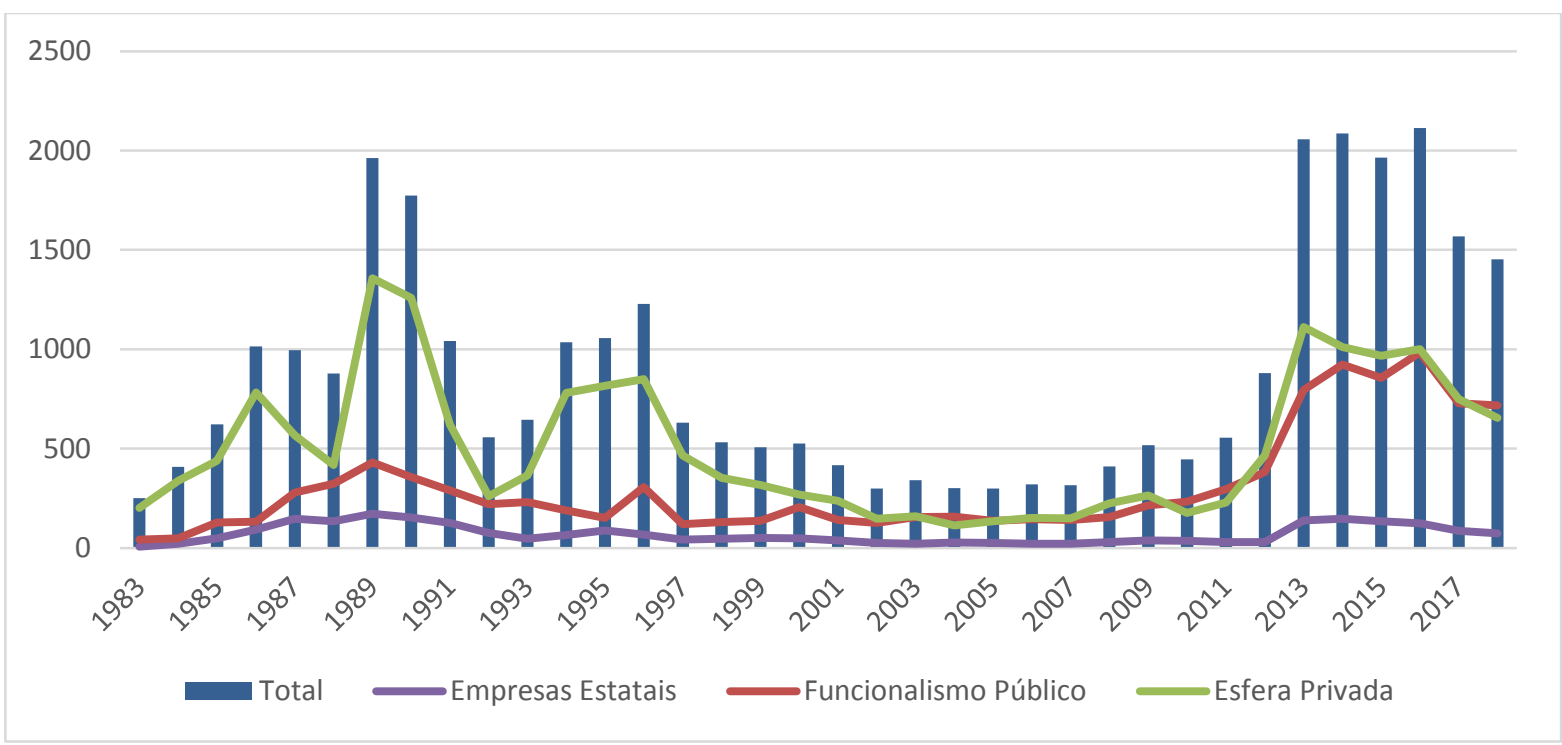

Fonte: SAG-DIEESE

Antes disso, boa parte dos anos 1980 e 1990 seriam de grande atividade grevista. Apesar das poucas greves no início dos 1980 e de uma relativa queda entre 1990 e 1993, as greves

3 Trotsky tratava as greves como políticas pelo fato de que a Rússia ainda era submetida a um regime tzarista de governo que considerava as greves ilegais. Por isso mesmo, cada greve realizada ganhava um sentido eminentemente político. 
foram a tônica do período até 1996, sendo um contraponto histórico importante para entendermos os anos seguintes de refluxo e os anos atuais de ressurgimento.

Essas greves têm sua origem alguns anos antes da série levantada pelo DIEESE. Eram produto da própria crise da ditadura militar brasileira, que se arrastava desde meados dos anos 1970 e tiveram como catalisador o movimento grevista dos trabalhadores metalúrgicos do ABC paulista. Inaugurava-se o ciclo grevista que criaria as bases para a fundação do PT em 1980 e da CUT em 1983. Também ali estava o substrato material da radicalidade originária dessas organizações ${ }^{4}$. O ciclo teria início com a greve deflagrada pelos trabalhadores da Scania de São Bernardo do Campo em 1978. Os operários daquela fábrica, reivindicando um reajuste salarial de $20 \%$ acima do que a Justiça do Trabalho lhes havia concedido (39\%), seriam o 'estopim' para a deflagração de greves em praticamente a totalidade do setor metalúrgico da região, o que impulsionaria outras várias categorias a também se agitarem politicamente (MATTOS, 2009).

Em 1978, ocorreram mais de cem greves no país; e no ano seguinte já haviam mais que duplicado em número. Foram movimentos que pararam metalúrgicos, motoristas e cobradores de ônibus, médicos, professores, garis, operários da construção civil, canavieiros, entre muitas outras categorias profissionais, atingindo um contingente de cerca de 3 milhões de trabalhadores (MATTOS, 2009, p. 118-119).

Após um primeiro ciclo de crescimento no número de greves, em 1978 e 1979, os primeiros anos da década de 80 assistiriam a uma contenção das ações grevistas. Tratava-se de uma conjuntura marcada pelo desemprego, pela crise econômica e com empresariado e governo já preparados para enfrentá-las, por meio do endurecimento nas negociações e do acionamento dos mecanismos repressivos da legislação sindical. A partir de 1983, entretanto, voltou a crescer a incidência de greves e os anos seguintes foram marcados por um ritmo intenso e inédito dos movimentos grevistas, indicando uma fase de intensa atividade sindical (MATTOS, 2009, p. 120)

Nesse ensejo, algumas questões ganham destaque. Em primeiro lugar, o papel fundamental da crise econômica que embaraçava a capacidade de hegemonia da ditadura desde a metade dos anos 1970. Tal crise, por sua vez, revertia-se em forte crescimento inflacionário que se arrastaria durante a década de 1980 e o início dos anos 1990. Essa expansão nos preços, após décadas de congelamento salarial promovido pela política econômica da ditadura militar, tratou de impulsionar as greves, mesmo sob o jugo dos aparelhos de repressão.

O surgimento do PT e da CUT, por sua vez, traria um salto organizativo nas lutas. As greves atingiriam novas categorias, seriam mais numerosas por conta das paralisações por empresas e por algumas importantes greves nacionais. A criação dos instrumentos organizativos também propiciou a unificação das lutas de diversas categorias em torno de pautas claramente políticas, como a reforma agrária e a suspensão do pagamento da dívida externa. Tudo isso confluiu para a grande greve geral de 1989, com a participação de mais de 20 milhões de trabalhadores por dois dias (MATTOS, 2009).

4 Os primeiros congressos do partido e da central eram marcados pela presença massiva de operários e camponeses, vários deles lideranças de processos grevistas. 
Toda essa agitação por parte da classe trabalhadora tratava de encarecer o próprio preço da força de trabalho no Brasil. Se para o capitalista é fácil utilizar da sua prerrogativa enquanto comprador de força de trabalho no mercado e substituir esses trabalhadores em momento de greve localizada, isso se inverte quando a conjuntura torna-se de greves de massa. Essa conjuntura deve ser entendida não como uma ação única, mas como um período de luta de classes que se estende por vários anos, às vezes por décadas, sendo que os elementos econômicos e políticos se entrelaçam, abrindo-se um cenário de radicais mudanças e impondo o debate sobre as formas organizativas que tomarão a direção política desse processo (LUXEMBURGO, 1974, p. 52-65). As greves de massa impõem dificuldades imensas para o capital, que não consegue rebaixar os salários de forma sistêmica, uma das contratendências necessárias para a saída de suas crises oriundas da lei tendencial de queda da taxa de lucro (MARX, 2008).

Era urgente para a classe dominante brasileira enfrentar o cenário de greve de massas, já que sua continuidade impôs ao capital o risco da vitória de um programa popular e radical nas eleições de $1989^{5}$. Dessa forma, já sob a batuta do governo José Sarney, seria iniciado no Brasil todo o programa de ajuste da nossa economia, sustentado pelo Consenso de Washington, e que daria início ao chamado neoliberalismo. Em uma primeira etapa, ainda nos anos 1980, deu-se um conjunto de reformas visando à estabilização dos preços através de cortes nos gastos públicos e elevação nas taxas de juros. Já na segunda etapa, atravessando toda a década de 1990, foram propostas e implementadas reformas estruturais que visavam à abertura comercial, às privatizações e à flexibilização do trabalho (KATZ, 2016).

Todas essas reformas teriam como eixo central a desestruturação dos pilares que haviam impulsionado a ascensão das greves de massa. De um lado, a inflação era combatida com a abertura comercial e a paridade cambial; de outro, a reestruturação produtiva e as privatizações levadas à frente em um processo de ampla centralização de capital impunham novos padrões de exploração e organização da força de trabalho. As classes médias urbanas, por sua vez, sendo atendidas em seus anseios por democracia representativa e já sentindo a redução dos preços via importação, abandonavam as ruas logo após a campanha pelo impeachment de Fernando Collor (1992).

Paralelamente, a CUT registrava uma inflexão em sua trajetória política original (acompanhando o movimento do próprio PT). Após uma primeira fase de ação sindical combativa e de confronto (1983-1988), a central passa por uma fase de transição (19881991) para, posteriormente, viver uma nova etapa de sindicalismo propositivo e negociador (TUMOLO, 2002).

Trata-se, portanto, de uma mudança política substancial, de um sindicalismo combativo e de confronto, de cunho classista e com uma perspectiva socialista, para uma ação sindical pautada pelo trinômio proposição/negociação/participação dentro da ordem capitalista que,

5 É importante lembrar que a soma dos votos de Lula da Silva e Leonel Brizola no primeiro turno de 1989 superava largamente a votação de Fernando Collor. O primeiro, naquele momento, ainda era associado ao radicalismo advindo das greves (diferentemente do Lula de 2002), e o segundo era o principal representante da esquerda do pré-1964. 
gradativamente, perde o caráter classista em troca do horizonte da cidadania. (TUMOLO, 2002, p. 129)

Como resultado dessas mudanças estruturais na economia e desse transformismo das organizações da classe trabalhadora, o capital ficaria livre para implementar, durante os anos 1980 e especialmente nos anos 1990, um padrão de especialização exportadora, que viria a recriar a inserção internacional do Brasil na divisão internacional do trabalho. Avança-se para uma internacionalização e modernização da agricultura e da mineração exportadora e registra-se um retrocesso da indústria tradicional e da produção de ciência e tecnologia como resultado da importação de produtos manufaturados do leste asiático. Ademais, é acelerada a conversão da velha burguesia nacional em mera burguesia local, intensificando a criação de grandes conglomerados capitalistas que envolvem todas as frações do capital dentro de uma mesma estrutura administrativa operada globalmente. Por fim, nas classes populares, desestrutura-se o velho campesinato, criando populações excedentes nas cidades que passam a viver em situação aguda de pobreza, informalidade e criminalidade; estreitando-se as condições de ascensão social das camadas médias, que perdem a indústria de transformação e o Estado como espaços de emprego melhor remunerado e ampliando-se a superexploração da força de trabalho, com sua rotatividade e baixos salários, como elemento constitutivo da dependência e do subdesenvolvimento brasileiro e latino-americano (KATZ, 2016, p. 19-35).

Entretanto, resta saber quais os motivos para que, mesmo dentro dessa degeneração das condições de vida da classe trabalhadora, ela tenha se comportado de forma passiva desde 1997 até 2011, o que é claramente expresso no marasmo grevista do período.

\section{Ideologia e forma salário}

Mauro Iasi, na esteira da formulação sobre o apassivamento da classe trabalhadora, afirma que a ideologia lhe parece ser "[...] a categoria essencial para compreender o movimento da consciência da classe trabalhadora e seu atual momento de impasse" (IASI, 2013a, p. 69). Propõe, corretamente, que a ideologia não se restringe a um conjunto de ideias produzidas e divulgadas pela classe dominante que, ao deter os meios de produção, teria a capacidade de apresentar suas ideias como universais perante a classe trabalhadora. Isso explicaria apenas como as ideias seriam lançadas, entretanto, não explicaria qual a razão de os trabalhadores, mesmo sendo explorados pela ordem dominante, aceitarem as ideias de seus algozes como suas.

Marx e Engels (2017) resolvem tal problema ao compreenderem a totalidade da produção material da vida. Afirmam a conexão inexorável entre estrutura social e política de determinada sociedade com a produção, ou seja, com o modo de produção de determinado período. A produção das ideias e as representações da consciência estariam, em princípio, imediatamente entrelaçadas com as atividades da vida material e do intercâmbio material dos homens. Nesse sentido, a relação direta das ideias se dá com o processo de vida real, com a linguagem do cotidiano.

Diante disso, a primeira forma de consciência da classe trabalhadora é a própria consciência burguesa ou a consciência da totalidade histórica concreta burguesa que é produzida pelos próprios trabalhadores em seu processo de vida diário. Tal processo 
produz e reproduz cotidianamente os próprios pressupostos da acumulação capitalista: trabalhadores assalariados e capitalistas. Constitui-se, assim, um sistema orgânico cujas partes se encontram articuladas por determinada totalidade, submetendo todos os elementos da sociedade ou criando para si os órgãos que lhe falta e configurando, dessa forma, seu processo de desenvolvimento (KOSIK, 1976).

A consciência imediata dos trabalhadores, a ideologia do cotidiano, não pode ser entendida distanciada da forma imediata da reprodução dos indivíduos sociais trabalhadores, ou seja, do trabalho assalariado. Assim, Iasi (2013b) aponta acertadamente para a consciência burguesa como primeira forma de expressão da consciência da classe trabalhadora. A partir daí, constata que essa primeira forma de conceber o mundo oferece substância para o apassivamento da classe trabalhadora, ou seja, seu amoldamento à ordem burguesa e questiona-se sobre como pensar a ruptura com essa ordem ou, mais especificamente, a ruptura com o apassivamento. $\mathrm{O}$ autor ainda chama atenção para o fato de que a sociabilidade burguesa, apesar de representar uma unidade material, é constituída sobre uma cisão de interesses de classe opostos, antagônicos e irreconciliáveis, que constituem uma totalidade. O ser da classe - e, por isso, sua consciência - se expressa em forma de contradição em movimento no interior da totalidade. Afirma, assim, que em determinados momentos a classe se comporta no sentido do amoldamento, submetida ao fenômeno do estranhamento,

Em outro momento vemos os trabalhadores se revoltando, entrando em luta, reivindicando suas demandas imediatas, aqui e ali, explodindo em formas mais avançadas de luta contra a ordem capitalista. Em situações mais precisas e raras podemos ver os trabalhadores levantando-se em movimentos históricos significativos, rompendo a ordem burguesa, ousando ir além dela, derrubando o estado burguês, iniciando experiências socialistas (IASI, 2013b, p. 73).

Qual é o momento de passagem de uma situação para outra? Como se dá a metamorfose da consciência da classe em si para a consciência da classe para si? Essa pergunta se impõe e Iasi responde-a afirmando que existe um momento anterior à própria consciência da classe em si. Tal momento corresponderia à concorrência entre os indivíduos isolados e pulverizados, que desagrega os proletários ao invés de colocá-los unidos como classe. Somente no momento de conflito contra o capital e da vivência das contradições dessa forma particular da produção social estariam dadas as condições objetivas para a manifestação da consciência em si, ainda sob os limites da ordem, e a possibilidade da passagem à consciência para si, já no bojo da construção de uma sociedade para além do capital (IASI, 2013b).

Por isso mesmo, o autor recorre às greves do final dos anos 1970 como fatores de construção da classe em si que, como passo seguinte, ensaiaria os germes da constituição da classe para si ao apontarem o projeto socialista da origem do PT e da CUT. Entretanto, algo fica sem resolução nesse salto entre a concepção teórica acertada do momento predecessor à consciência em si e o momento das greves, ou das greves de massa, tal como formulamos anteriormente. O salto não é explicado, na nossa avaliação, pela ausência de uma caracterização concreta da base material que sustenta a ideologia dos trabalhadores isolados e pulverizados enquanto indivíduos, qual seja, a forma salário. 
À forma aparente, 'valor e preço do trabalho' ou 'salário', em contraste com a relação essencial que ela dissimula, o valor e o preço da força de trabalho, podemos aplicar o que é válido para todas as formas aparentes e seu fundo oculto. As primeiras aparecem direta e espontaneamente como formas correntes de pensamento; o segundo só é descoberto pela ciência (MARX, 2005, p. 622).

Se ao trabalhador aparece a forma salário como sua primeira apreensão da sociedade capitalista, ao trabalho científico cabe desvelar os movimentos do valor e do preço da força de trabalho. Dessa forma, o essencial é compreender os desdobramentos da lei geral da acumulação capitalista na sociedade brasileira, desvendando em sua totalidade a maneira como a reprodução do capital e suas crises impactam diretamente no nível da demanda por força de trabalho, em seu valor e em seu preço - ou, em outras palavras, na forma imediata como o trabalhador assalariado produz e organiza sua própria existência. Esse dado é fundamental pelo fato de que é justamente nos momentos de crise do capital em uma determinada temporalidade e espacialidade (como a partir da metade dos anos 1970 no Brasil) que fissuras podem abrir-se na própria forma salário. Através de fenômenos como a inflação, o desemprego e o rebaixamento salarial, a passividade dos trabalhadores entra em xeque, revertendo-se em expansão das greves e agitação social.

Isso ocorre porque a forma salário somente existe como parte do ciclo do próprio capital. Compreendê-la, em última instância, é apreender a metamorfose do capital-dinheiro em capital-produtivo. Mais especificamente, as formas concretas como os vários capitalistas individuais, movidos pela busca do lucro extraordinário, definem a compra dos elementos do capital produtivo: meios de produção e força de trabalho. Além disso, pelo fato de ser necessário que essas operações sejam repetidas periodicamente, elas compõem um ciclo de reprodução do capital. Dialeticamente, o trabalhador produz o capital e o capitalista produz o trabalhador assalariado.

O próprio trabalhador produz, por isso, constantemente, riqueza objetiva, mas, sob a forma de capital, uma força que lhe é estranha, o domina e explora, e o capitalista produz também, constantemente a força de trabalho, mas sob a forma de uma fonte subjetiva de valor, separada dos objetos sem os quais não se pode realizar, abstrata, existente apenas na individualidade do trabalhador, em suma, o capitalista produz o trabalhador sobre a forma de trabalhador assalariado. Essa reprodução constante, essa perpetuação do trabalhador é a condição necessária da produção capitalista (MARX, 2006, p. 666).

Assim, a forma salário, apesar de reproduzir trabalhadores individualizados, contém em si mesma sua negação: a contradição entre os produtores (trabalhadores) e a forma alienada da sua produção apropriada privadamente pelos capitalistas. Aqui está o caráter fundamental da greve tal como colocado por Álvaro Vieira Pinto (1962) em passagem anteriormente desenvolvida: deixar de trabalhar para o capitalista e passar a trabalhar para si (fundamento da construção da classe em si). O que deflagraria, então, o salto da forma apassivada da classe - ou, melhor dizendo, atomizada e fragmentada - para uma forma de contestação grevista?

A resposta é a própria crise da reprodução do capital, a crise de seu ciclo, quando as metamorfoses sucessivas entre as fases do capital tornam-se truncadas ou até mesmo 
paralisam-se. Entretanto, a forma concreta como essas crises aparecem e como se dá a reação dos capitalistas, do Estado e dos trabalhadores são condicionadas pela particularidade histórica e espacial onde ocorrem. Particularidade que, no caso brasileiro, conforma parte do bloco das economias dependentes latino-americanas (MARINI, 2005, p. 138-139).

\section{O novo ciclo grevista no Brasil}

Os dados exibidos no gráfico 1 sustentam a tese de que passamos a viver desde 2012 uma nova retomada das greves de massa no Brasil. Diante disso, a própria ideia de apassivamento da classe passa a ser questionada. Se as críticas ao transformismo do PT e ao papel da ideologia são acertadas, mostram-se insuficientes por abdicarem de uma caracterização concreta dos elementos que constituem o ciclo do capital na economia dependente e a forma como isso repercute na reprodução dos trabalhadores assalariados. Por isso mesmo, teses como a do apassivamento deveriam estar assentadas sobre uma teoria do próprio desenvolvimento capitalista em um país subdesenvolvido e dependente, para além da discussão sobre os condicionantes abstratos e universais da produção capitalista e da ideologia. Ao não expandirem o debate sobre a forma salário para o ciclo de reprodução do capital na economia dependente, tornou-se impossível aos estudiosos do tema perceberem o momento de inversão da conjuntura política da classe trabalhadora.

A análise da particularidade histórica do desenvolvimento do capitalismo dependente brasileiro permitiria demonstrar que, nem tanto sob o efeito da crise capitalista de 2008, mas muito mais sob as refrações dessa crise na queda dos preços das matérias primas internacionais (ocorridas a partir de 2011), estaria o fundamento da reascensão grevista no Brasil. Em um país dependente de especialização exportadora, a queda desses preços constituiu um momento decisivo.

Segundo dados da Funcex, a queda foi de 35,8\% entre 2011 e 2016, sendo especialmente vertiginosa a diminuição do preço dos produtos agrominerais ( $72 \%$ no petróleo, $78 \%$ no minério de ferro e $46 \%$ na soja). Isso foi fundamental, já que o "apassivamento" anterior teve sustentação na política de controle inflacionário do governo Fernando Henrique Cardoso e na política de crédito para consumo do governo Lula da Silva, ambas garantidas por ciclos de expansão dos preços internacionais, as quais minimizavam os efeitos nocivos da transferência de valor da periferia para o centro trazida pela situação estrutural de dependência (MARINI, 2005, p. 150-151).

Aqui a análise do apassivamento da classe trabalhadora perde força uma vez que não incorpora as contribuições críticas da teoria marxista da dependência que, desde os anos 1960 e antes mesmo do golpe militar, já teorizava sobre o ciclo do capital, suas crises e seu impacto nas lutas sindicais (OURIQUES, 2014, p. 24). Em nossa concepção o resgate apenas de Florestan Fernandes e Caio Prado Jr. como críticos da estratégia da Revolução Nacional Democrática do PCB no pré-1964 deixa de fora toda uma tradição composta por intelectuais do calibre de Ruy Mauro Marini e Álvaro Vieira Pinto, entre outros, que também haviam criticado e rompido com a estratégia do PCB no pré-64. Também limita a compreensão sobre o apassivamento o fato de lasi (2013b) não se referir à forma como 
o discurso originário do PT se diferenciava não apenas da estratégia do $\mathrm{PCB}$, mas também combatia a herança do nacionalismo radical representada por Leonel Brizola e a sua insistência em torno daquilo que chamava perdas internacionais.

Esse alerta é fundamental, já que é a tradição da teoria marxista da dependência que sustenta a análise defendida aqui de que foi a queda do preço dos produtos de exportação, diante de uma economia dependente em processo acelerado de especialização exportadora desde os anos 1990, que levou à nova expansão vertiginosa das greves no Brasil. Isso fica claro no caráter das greves inauguradas em 2012. Diferentemente dos anos 1980, quando as greves tinham caráter ofensivo (basicamente buscavam ganhos salariais contra a inflação), as novas greves são essencialmente defensivas. São greves que visam essencialmente a contenção da retirada de direitos trabalhistas nos próprios locais de trabalho (como salários atrasados, não pagamento de $13^{\circ}$ salário e retirada ou reajustes nos valores de planos de saúde, vale alimentação e vale transporte).

\section{Gráfico 2 - Caráter das greves no Brasil (1983-2018)}

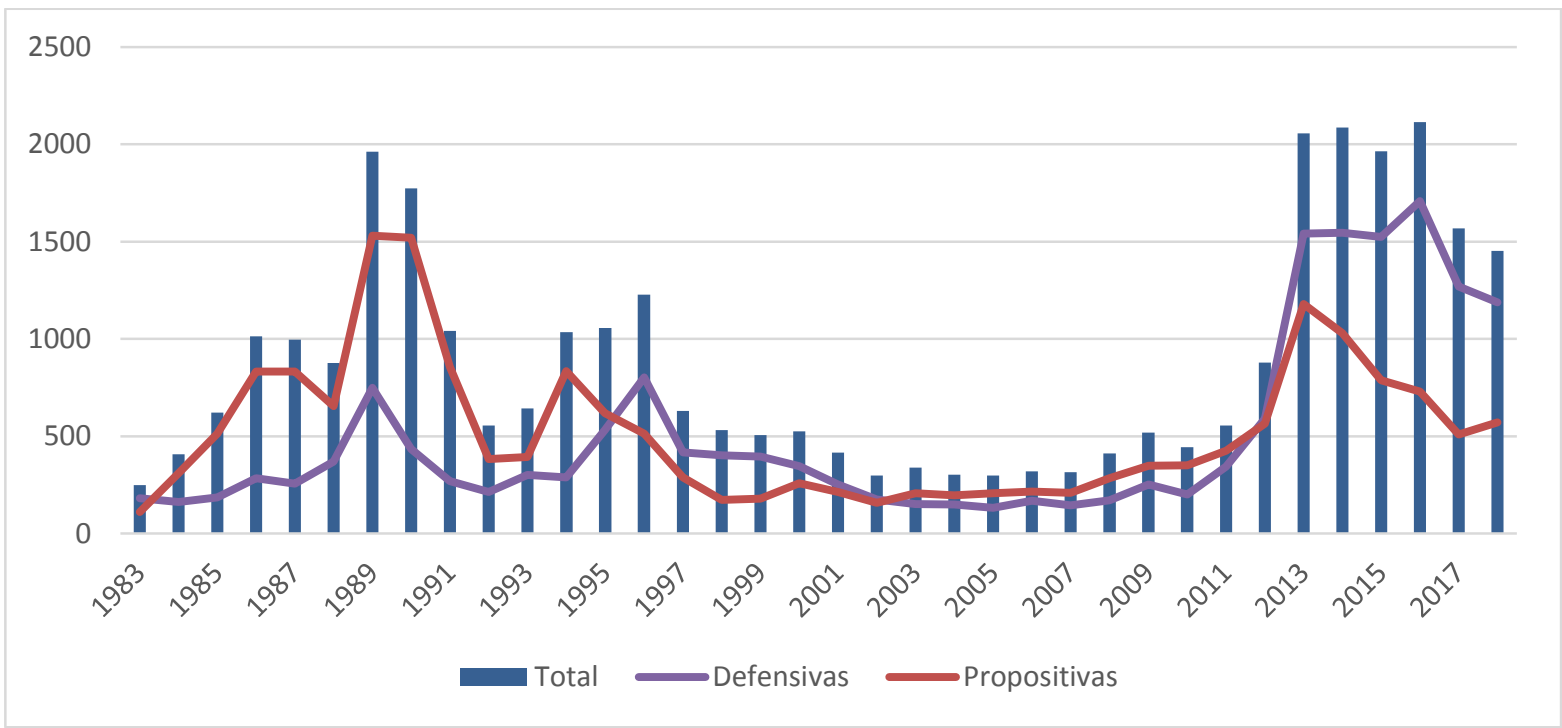

Fonte: SAG-DIEESE

Diante dos primeiros sintomas de queda dos preços internacionais - e, consequentemente, de redução das taxas de lucro das grandes empresas transnacionais do modelo de especialização exportadora brasileiro ${ }^{6}$ - o capital passaria a intensificar duas contratendências de reposta à crise preponderantes em países dependentes: $o$ aumento da taxa de exploração da força de trabalho e a redução dos salários.

Mesmo assim, em um primeiro momento, ainda foi possível vislumbrar um número significativo de greves ofensivas nos anos de 2012 e 2013, que entraria em queda vertiginosa a partir de 2014. O fato é que a taxa de desemprego no Brasil era baixíssima

${ }^{6}$ Lembrando que um dos fatores contrários à lei tendencial de queda da taxa de lucro da economia capitalista é o rebaixamento do preço dos elementos do capital constante. Ou seja, como resposta à crise capitalista que atingiu os países centrais em 2008, a retração de sua demanda por matérias primas da periferia trataria de rebaixar seus preços, auxiliando na superação do ponto mais agudo da crise.

Argum., Vitória, v. 12, n. 1, p. 162-175, jan./abr. 2020. | ISSN 2176-9575 
anteriormente a 2015, exatamente em função do ciclo de expansão da economia dependente puxado pelos preços internacionais, o que dava segurança aos trabalhadores na disputa grevista e provocava a ira das entidades empresariais.

Ambos os pontos passam a ser revertidos drasticamente na virada de 2014 para 2015. O capital, então, utiliza-se de uma terceira contratendência diante de sua crise: a ampliação da superpopulação relativa. De um lado, verificamos um novo ciclo de importação das novas tecnologias de exploração da força de trabalho criadas no centro capitalista logo após a grande crise de 2008 , aquelas que impõe a chamada uberização da força de trabalho7 ${ }^{7}$. Essas, ao aumentarem significativamente a produtividade, liberam força de trabalho dos processos de produção de capital. Por outro lado, a própria presidente Dilma Rousseff aplicou um ajuste fiscal de caráter recessivo logo após sua reeleição em 2014. Esse ajuste retiraria direitos trabalhistas e cortaria drasticamente investimentos públicos, o que faria ampliar sobremaneira a taxa de desemprego no Brasil calculada pelo IBGE, que salta de em torno de $4,5 \%$ no início de 2015 , para mais de $12 \%$ ao final do mesmo ano.

Dali em diante, as greves diminuem, caindo $41 \%$ no primeiro semestre de 2019, totalizando 529 paralisações contra 899 no primeiro semestre de 2018 (CRISE..., 2019). Mesmo assim, não é possível afirmar que esse dado seja permanente para os próximos anos e, mesmo que as greves tenham caído, elas continuam em patamar elevado na comparação com os números do dito ciclo de apassivamento.

\section{Considerações finais}

Se é possível caracterizar o atual ciclo grevista como uma reedição do debate clássico sobre as greves de massa, sua retração a partir da política implementada no governo de Dilma Rousseff em 2014/2015 ainda precisa ser acompanhada para melhores conclusões. O ataque aos trabalhadores e sua desarticulação não se encerraram com Dilma Rousseff, sendo que tanto Michel Temer quanto Jair Messias Bolsonaro continuaram a política econômica que visa recuperar a taxa de lucro do capitalismo dependente através da ampliação da superexploração da força de trabalho.

Por outro lado, foram os próprios sindicatos cutistas que auxiliaram o governo petista na aplicação dessa política quando de seu início. Esse dado, que corrobora parte da tese sobre o apassivamento defendida por Iasi e outros autores não pode ser descartado: o transformismo do PT e suas direções sindicais. Entretanto, os limites dessa tese também se impõem, já que a resposta dos trabalhadores a esse ataque operado pelas mãos de seus antigos dirigentes não foi a mesma que aquela verificada após as reformas antipopulares de 2003 feitas por Lula da Silva, por exemplo. A resposta foi o próprio repúdio à esquerda articulada em torno do petismo e ao sindicalismo cutista, que se manifestou tanto

\footnotetext{
7 Como fenômeno paradigmático desse processo, temos exatamente em 2014 a chegada da UBER no Brasil, empresa que havia sido criada em 2009 na Califórnia. Esse fenômeno incidiria sobremaneira sobre o setor de serviços, exatamente aquele que contava com a maior absorção de força de trabalho nos anos anteriores (APP..., 2014).
} 
durante o processo de impeachment de Dilma Rousseff quanto na eleição de Jair Messias Bolsonaro em 2018.

Aliás, a queda significativa das greves em 2019 não pode desconsiderar o efeito que essa eleição teve sobre a classe trabalhadora brasileira. Contraditoriamente, o presidente que agora promove ataques como a reforma da previdência foi o depositário da confiança dos trabalhadores contra a crise capitalista que está em curso desde 2012 (quando do início do novo ciclo grevista), trabalhadores que ainda não se arriscam em greves que atacariam o próprio governo. Entretanto, o seu programa econômico, comandado por Paulo Guedes, é apenas uma intensificação das exigências do capitalismo dependente brasileiro em sua etapa de especialização exportadora, ou seja, não tem capacidade de estabilizar os aspectos relativos à forma salário, inviabilizando, ao menos em curto e médio prazo, uma nova estabilidade econômica para a classe trabalhadora.

Os índices de popularidade do presidente despencam rapidamente nesse contexto. Para além dos discursos ou das formas que a ideologia se apresenta do ponto de vista da política, consideramos necessário voltar os olhos para a forma salário dentro da dinâmica capitalista da economia dependente brasileira. Essa nos mostra que o futuro dessa quadra da luta de classes ainda é um caminho em aberto, sendo a teoria a única bússola que dispomos para nos orientar diante das contradições e lutas que certamente virão.

\section{Referências}

APP de caronas sensação nos EUA, Uber chega a São Paulo. G1, São Paulo, 28 de jun. de 2014. Disponível em: http://g1.globo.com/tecnologia/tem-umaplicativo/noticia/2014/o6/app-de-caronas-sensacao-nos-eua-uber-chega-saopaulo.html. Acesso em: 13 out. 2019.

CRISE e sindicato mais pobre derrubam número de greves. Valor, São Paulo, 16 de set. de 2019. Disponível em: https://valor.globo.com/brasil/noticia/2019/o9/16/crise-esindicato-mais-pobre-derrubam-numero-de-greves.ghtml. Acesso em: 13 out. 2019.

FONTES, Virgínia. O Brasil e o capital-imperialismo: teoria e história. Rio de Janeiro: EPSJV, UFRJ, 2010.

IASI, Mauro Luis. Democracia de cooptação e o apassivamento da classe trabalhadora. Partido Comunista Brasileiro, 18 mar. 2013a. Disponível em: https://pcb.org.br/portal2/4487/democracia-de-cooptacao-e-o-apassivamento-daclasse-trabalhadora/. Acesso em: 3 out. 2019.

IASI, Mauro Luis. Educação e consciência de classe: desafios estratégicos. PERSPECTIVA, Florianópolis, v. 31, n. 1, 67-83, jan./abr. $2013 \mathrm{~b}$.

KATZ, Claudio. Neoliberalismo, neodesenvolvimentismo, socialismo. São Paulo: Expressão Popular, 2016.

KOSIK, Karel. Dialética do Concreto. Rio de Janeiro: Paz e Terra, 1976. 
LENIN, Vladimir Ilich. Sobre as greves. 1924. Disponível em: https://www.marxists.org/portugues/lenin/1899/mes/greves.htm. Acesso em: 3 out. 2019.

LUXEMBURGO, Rosa. Greve de massas, partidos e sindicatos. Coimbra: Centelha, 1974.

MARINI, Ruy Mauro. Dialética da dependência. In: TRASPADINI, Roberta; STEDILE, João Pedro (Orgs.). Ruy Mauro Marini: vida e obra. São Paulo: Expressão Popular, 2005 .

MARX, Karl. O capital: crítica da economia política. Livro 3: o processo global de produção capitalista. Rio de Janeiro: Civilização Brasileira, 2008.

MARX, Karl. O capital: crítica da economia política. Livro 1: o processo de produção do capital. Rio de Janeiro: Civilização Brasileira, 2006.

MARX, Karl; ENGELS, Friedrich. A ideologia alemã. São Paulo: Boitempo, 2017.

MATTOS, Marcelo Badaró. Trabalhadores e sindicatos no Brasil. São Paulo:

Expressão Popular, 2009.

OURIQUES, Nildo. O colapso do figurino francês: crítica das ciências sociais no Brasil. Florianópolis: Editora Insular, 2014.

PINTO, Álvaro Vieira. Por que os ricos não fazem greve? Rio de Janeiro: Civilização Brasileira, 1962.

TROTSKY, Leon. A história da revolução russa: a queda do tzarismo. Rio de Janeiro: Paz e Terra, 1967.

TUMOLO, Paulo Sergio. Da contestação à conformação: a formação sindical da CUT e a reestruturação capitalista. Campinas: Editora da Unicamp, 2002. 